\title{
Efficacy of Parenteral Granisetron in the Prevention of Post-Operative Nausea and Vomiting
}

\author{
JU AHMED ${ }^{\mathrm{a}}, \mathrm{S} \mathrm{NOOR}^{\mathrm{b}}$, MA HOSSAIN $^{\mathrm{c}}$, MM HOSSAIN ${ }^{\mathrm{d}}$
}

\begin{abstract}
Summary:
Post-operative nausea and vomiting (PONV) is one of the most unpleasant complications following anaesthesia and surgery since long time. A non -randomized case control study of prevention of post operative nausea and vomiting with IV-Granisetron was done on 270 adult surgical patients who received general or spinal aneasthesia. All the patients were followed up to 48 hours after operation. A complete response was achieved in prophylaxis group
\end{abstract}

\section{Introduction:}

PONV is one of the most unpleasant complications following anaesthesia and surgery prior to 1960 , when older inhalational agents such as ether and cyclo propane were widely used, the incidence of vomiting was reported to be as high as $60 \% 1,2$. Better anaesthetic techniques along with a newer generation of antiemetics and shorter acting anaesthetic drugs reduced the incidence of PONV to about $25-30 \%$ in todays practice. Nevertheless , PONVstill occurs, with an incidecne as high as 60$70 \%$ in some high risk patients ${ }^{3,4}$.Incidence is lower in children less than 2 years of age 5,6 .

Some procedures like tonsillectomies, strabismus surgery, laparoscopic cholecystectomies are associated with high incidence of PONV ${ }^{7,8}$.High level of anxiety and post operative pain, specially pelvic or visceral origin may also be associated with higher incidence of PONV ${ }^{9-11}$.

a. Dr. Jashim Uddin Ahmed, Associate Professor, Department of Surgery, Chittagong Medical College Hospital

b. Dr. Serajun Noor, Junior Consultant, Gynae \& Obst., Chittagong Medical College Hospital

c. Dr. Md. Anisul Hossain, Assistant Registrar, Surgery, Chittagong Medical College Hospital

d. Prof. Md. Margub Hossain, Professor of Surgery, Dhaka Medical College Hospital

Address of Correspondence: Dr. Jashim Uddin Ahmed, Associate Professor, Department of Surgery, Chittagong Medical College Hospital

Received: 21 June, 2007

Accepted: 21 June, 2009 as $92.6 \%$ and in control group as $90.4 \%(p-v a l u e=0.6637)$. In patient with $P O N V$,gender incidence is equal in prophylaxis group. Female incidence is higher in control group. Majority of patients (90 to $100 \%$ ) had PONV within 24 hours after operation. As there is insignificant difference in the achievement between prohylaxis group and control group, anti emetic prophylaxis is recommended only for patient with one or more risk factors for PONV.

(J Bangladesh Coll Phys Surg 2009; 27: 139-143)

Apfed et al, developed a simplified risk score consisting of four predicitors- female gender, history of motion sickness or PONV, non smoking status and use of opoids for post operative analgesia ${ }^{3}$.

Ambulatory patients appear to have lower incidence of PONV compared with in- patients ${ }^{12}$.

PONV may result in delayed hospital discharge , decreased patient satisfaction, increased use of resources including medical and nursing care and other supplies ${ }^{13}$.

Prevention of PONV is very important to patients and nation as well. Granisetron is an effective anti emetic belongs to serotonin antagonist having less adverse effects. We tried to evaluate the efficacy of Granisetron and justification of its use in prevention of PONV in general surgery unit.

\section{Methodology:}

Type of study : Non randomized case control study.

Study period : 14 July 2005 to 14 December 2005.

Place of study : In a general surgery unit, Chittagong Medical College Hospital.

Study population: For case group/ prophylaxis, all the patients have under gone general surgical operations of different types, irrespective of general or spinal anaesthesia and sex, received IV Granisetron $1 \mathrm{ml}(1 \mathrm{mg})$.

For control group: Those who did not receive IV Granisetron. 
Sample size: The sample size was calculated by using software open Epi version 2007, by accepting the incidence of PONV after G.A/ spinal Anesthesia approximately $60 \%$ to ensure $95 \%$ confidence interval and power 80, 283 patients in each group.

Selection criteria : (For both control and prophylaxis group).

Inclusion criteria - All routine \& emergency operations done in a surgical unit under GA or SA. Patients of both sexes are included .

Exclusion criteria - Patients who are unwilling to receive the study drug. Operations done under LA. Paediatric surgical cases - age below 15 years.

In every alternate patient Granisetron $1 \mathrm{mg} / 1 \mathrm{ml}$ was introduced iv immediately after induction of anaesthesia. In other patients that is in control group no Granisetron was introduced and follow up were done up to 48 hours after operation for PONV \& recorded in separate proforma for each patient. Statistical analysis were done.

Follow up were done by the author, registrar and assistant registrar of the unit.

Post operative period was standardized with proper analgesia , rehydration and other management.

\section{Ethics}

Ethical clearance was obtained from the medical ethical clearance committee of Chittagong medical college. Proper written informed consents signed by the attendants were taken for each patient.

Limitation of the study: small sample size (135 patients in each group). Post study calculation showed the power $50.74 \%$.

\section{Results}

Out of 135 patients of prophylaxis group, PONV was recorded in 10 patients $(7.4 \%) .7$ patients had laparotomy for different surgical conditions, gender incidence was equal and $90 \%$ patients had PONV within 24 hours of operation.

In 135 patients of control group, PONV was recorded in 13 patients $(9.6 \%)$. 8 patients had laparotomy for different surgical pathologies, gender incidence was higher in female and $100 \%$ patients had PONV within 24 hours of operation.

A complete response, defined as no PONV and no need for another rescue anti-emetic,and was achieved as $92.6 \%$ and $90.4 \%$ in prophylaxis and control group respectively.

Almost all parameters used in this study are comparable between the control group and prophylaxis group.

Table-I

Summary of Patients with PONV in Prophylaxis Group:

\begin{tabular}{llccc} 
S1. No. & Operation & Anesthesia & Gender & Duration \\
\hline 1. & Gastro Jejunostomy & GA & F & $<24$ hours \\
2. & Laparotomy \& ileostomy & GA & M & $<24$ hours \\
3. & Repair of Rec. Ing. Hernia & SA & M & $<24$ hours \\
4. & Ovarian Cysctectomy & GA & F & $<48$ hours \\
5. & Cholecystectomy & GA & F & $<24$ hours \\
6. & Laparotomy \& Gut resection & GA & M & $<24$ hours \\
7. & Partial Gastrectomy & GA & F & $<24$ hours \\
8. & Cholecystectomy & GA & F & $<24$ hours \\
9. & Piles Operation & SA & M & $<24$ hours \\
10. & Repair of Hernia & SA & M & $<24$ hours \\
\hline
\end{tabular}


Table -II

Summary of Patients with PONV in Control Group:

\begin{tabular}{llccc} 
S1. No. & Operation & Anesthesia & Gender & Duration \\
\hline 1. & Laparotomy \& repair of DU perforation & GA & M & $<24$ hours \\
2. & Emergency appendicectomy & GA & F & $<24$ hours \\
3. & Repair of obstructed inguinal hernia & SA & M & $<24$ hours \\
4. & Rt. hemicolectomy & GA & F & $<24$ hours \\
5. & Repair of inguinal hernia & SA & F & $<24$ hours \\
6. & Rt. nephrectomy & GA & F & $<24$ hours \\
7. & Repair of inguinal hernia & SA & M & $<24$ hours \\
8. & Laparotomy for intestinal obstruction & GA & F & $<24$ hours \\
9. & Appendicular abscess drainage & GA & M & $<24$ hours \\
10. & Repair of inguinal hernia & SA & M & $<24$ hours \\
11. & Emergency appendicectomy & SA & F & $<24$ hours \\
12. & Interval appedicectomy & GA & F & $<24$ hours \\
13. & Emergency appendicectomy & SA & F & $<24$ hours \\
\hline
\end{tabular}

Table-III

Incidence of PONV

\begin{tabular}{lccc} 
& \multicolumn{2}{c}{ Incidence of PONV } \\
Total patients(n=270) & PONV & Complete response & P-value \\
\hline Prophylaxis group (135) & $10(7.4 \%)$ & $125(92.6 \%)$ & $\mathrm{P}=0.6637(\mathrm{~N} . \mathrm{S}){ }^{*}$ \\
Control group (135) & $13(9.6 \%)$ & $122(90.4 \%)$ & \\
\hline
\end{tabular}

"=Fisher's exact test. N.S= Non significant

Table -IV

\begin{tabular}{|c|c|c|c|c|c|c|c|}
\hline \multicolumn{8}{|c|}{ Comparative analysis } \\
\hline \multirow[t]{2}{*}{ Patient } & \multirow[t]{2}{*}{ PONV } & \multicolumn{2}{|c|}{ Gender } & \multicolumn{2}{|c|}{ Anaesthesia } & \multicolumn{2}{|c|}{ Period } \\
\hline & & Male & Female & General & Spinal & $0-24$ hrs. & 25-48 hrs. \\
\hline Prophylaxis Group & $\mathrm{N}=10$ & 5 & 5 & 7 & 3 & 9 & 1 \\
\hline Control Group & $\mathrm{N}=13$ & 5 & 8 & 7 & 6 & 13 & 0 \\
\hline
\end{tabular}

Table -V

Base line parameters

\begin{tabular}{lccc} 
Parameters & Prophylaxis group $\mathrm{n}=135$ & Control group $\mathrm{n}=135$ & P-value \\
\hline Mean age in years & $36.51 \pm 14.58$ & $37.71 \pm 15.03$ & 0.5063 \\
Sex -male: female & $93: 42$ & 82.53 & 0.1609 \\
Mean BMI & $29.83 \pm 5.2$ & $31.05 \pm 6.16$ & $0.245($ N.S) \\
ASA Score -I & 97 & 92 & 0.540 (N.S) $\S$ \\
\multicolumn{1}{c}{-II } & 38 & 43 & 0.670 (N.S) \\
\hline
\end{tabular}

$\pm=$ Standard deviation; $\quad \S=$ Chi squre test; $\quad$ N.S $=$ Non significant 


\section{Discussion :}

The etiology of PONV is multifactorial. Factors such as age, obesity, a history of motion sickness and / or previous PONV, menstruation, surgical technique / duration, postoperative pain, dehydration, among others, are considered to affect the incidence of PONV. Consequences are also many like electrolytes imbalance, dehydration, Mallory weis tear, wound dehiscence and haematoma formation ${ }^{14-17}$, Hospital and increased nursing care time contribute to the economic related consequences of PONV.

There appears to be a direct relationship between the incidence of PONV and the operative site, with a higher incidence of PONV after eye, oral, plastic, ENT, head neck surgery, gynae and Obstretic, Laparoscopic and abdominal procedures than with other procedures ${ }^{16-22}$.

In our study incidence of PONV was higher in different laparotomy procedures of both prophylaxis and control group. As the study was done in general surgical unit so the other parts were considered less frequently.

Female patients have a 2 to 3 times greater incidence of PONV than males, due to increased gonadotrophin, oestrogen \& plasma progesterone levels during menstrual cycle 19,23,24.

In the present study the gender incidence is equal in the prophylaxis group but female preponderance in control group.

In adults, there is a correlation between increasing age and decreasing incidence of PONV 19,25.

PONV are adverse effects of regional anaesthesia (spinal \& epidural), with an incidence of approximately 10 to $20 \%{ }^{14}$. The resulting incidence of PONV is due to decreased cerebral blood flow secondary to systemic hypotension, increased G.I. atony, vagal stimulation following intraabdominal G.I. manipulation 26,27 .

In our study group the incidence of PONV was observed more in patients having GA of both prophylaxis and control group. Probably because, majority of abdominal procedures were done in general surgical unit and mostly done under G.A.

The baseline parameters used in the study are- mean age of patients, sex male /female ratio, mean body mass index, ASA score $-1,11$ WBC count. With the exception of few all parameters are comparable between the control and prophylaxis group. The parameters which vary between the two groups of patients carry no importance in determining the outcome of the study.

Among numerous antiemetics, granisetron was found more effective. In one rendomised double blind study on 120 patients, granisetron was found more effective than droperidol and metoclopramide in the treatment of PONV 28

Granisetron lacks the sedative, dysphoric, extrapyramidal symptoms associated with other non -5HT receptor antagonist such as droperidal and metoclopramide ${ }^{29}$.

The most common adverse event associated with the study drug is headache, was not judged to be clinically serious, no other significant adverse events occured in any group.

The fact that granisetron is much more expensive than the traditional antiemetics may delay its wide spread use. This study did not include a cost effectives analysis ( cost per unit success) but to justify its use in cases with one or more risk factors for PONV.

\section{Conclusion:}

While we have achieved significant advances in the management of PONV, it still occurs frequently in high risk patients.Not all the patients will benefit from anti emetic prophylaxis, thus identifications of patients who are at increased risk is imperative. The major risk factors for PONV are female gender, non smoking status, history of PONV or motion sickness, use of volatile anaesthetics, itra operative or post operative opoids, increased duration of surgery, type of surgery ( laparoscopic, ENT, neurosurgery, breast, strabismus and plastic surgery).

We recommend anti emetic prophylaxis in patients with one or more risk factors for PONV, preferably with serotonin antagonist.

\section{Acknowledgement:}

We remember with honour Prof. Md. Ridwanur Rahman, Professor of Medicine, Khaleda Zia Medical College, Dhaka, Dr. S M Ashraf Ali, Assoc. 
Professor of Surgery Chittagong Medical College, for their valuable suggestions and advices in preparation of this article.

\section{References:}

1. Dent SJ, Ramachandra V, Stephen CR. Post. operative vomiting : incidence, analysis and therapeutic measures in 3000 patients. Anesthesiology 1955;16:564.

2. Water RM. Present status of cyclopropane. Br Med J 1936; 2:1013.

3. Apfel CC, Laara E, Koivuranta M, Greim CA, Roewer N. A simplified risk score for predicting postoperative nausea and vomiting : conclusions from cross validations between two centers. Anesthesiology 1999; 91:693-700.

4. Gan TJ, Ginsberg B, Grant AP, Glass PS, Glass PS. Double - Blind, randomized comparison of ondansetron and intraoperative propofol to prevent postoperative nausea and vomiting. Anesthesiology 1996; 85:1036-42.

5. Heyland K, Dangel P, Gerber AC. Postoperative nausea and voming (PONV) in children. Eur J Pediatr Surg 1997; 7:230-3

6. Rose JB, Watcha MF. Postoperative nausea and vomiting in paediatric patients. Br J Anaesth 1999;83:104-17.

7. Ved SA, Walden TL, Montana J, el al. Vomiting and recovery ater outpatient tonsillectomy and adenoidectomy inchildren. Comparision of four anesthetic techniques using nitrous oxide with halothane or propofol. Anesthesiology 1996;85:4-10.

8. Shende D, Bharti N, Kathirvel S, Madan R. Combination of droperidol and ondansetron reduces PONV after pediatirc strabismus surgery more than single drug therapy, Acta Anaesthesiol Scand 2001;45:756-60.

9. Andersen R, Krohg K. Pain as a major cause of postoperative nausea. Can Anaesthesia Soc J 1976;23:3669.

10. Jenkins LC, Lahay D. Central mechanisms of vomiting related to catecholamine response: anaesthetic implication. Can Anaesht Soc J 1971; 18:434-41.

11. Rees MR, Clark RA, Holdsworth CD. The effect of beta adrenoreceptor agonists and antagonists on gastric emptying in man. Br J Clin Pharmacol 1980;10:551-4.

12. Visser K, Hassink EA, Bonsel GJ, Moen J, Kalkman CJ. Randomized controlled trial of total intravenous anesthesia with propofol versus inhalation anesthesia with isoflurane nitrous oxide-postoperative nausea and vomiting and economic analysis. Anesthesiology 2001; 95:616-26

12. Hill RP, Lubarsky DA, Phillips Bute B, et al. Costeffectiveness of prophylactic antiemetic therapy with ondansetron, droperidol, or placebo. Anesthesiology 2000;92:958-67.
14. Palazzo MGA, Strunin L. Anaesthesia and emesis . I. etiology. Can Anaesth Soc J 1984; 31:178-87.

15. Patel R1. Hanallah RS. Anesthetic complications following pediatric ambulatory surgery: a 3-year study. Anesthesiology 1988;69:1009-12.

16. Larsson S, Jonmarker C. Postoperative emesis after pediatic strabismus surgery: the effect of dixyrazine compared to droperidol. Acta Anaesthesiol Scand 1990;34:227-30.

17. Dent SJ, Ramachandra V, Stephen CR. Postoperative vomiting:incidence, analysis, and therapeutic measures in 3000 patients. Anesthesiology 1955;16:564-72.

18. Honkavaara P. Effect of transdermal hyoscine on nausea and vomiting during and after middle ear surgery under local anesthesia . Br J Anaesth 1996; 76:749-50.

19. Philip BK. Etiologies of postoperative nausea and vomiting. Pharmacy ther 1997;22(7 Suppl.):18-25S.

20. Haigh CG, Kaplan LA, Durham JA. Nausea and vomiting after gynecological surgery: a meta analysis of factors affecting their incidence. Br. J Anaesth 1993; 71: 512-22.

21. Bellville J. Postanesthetic nausea and vomiting. Anesthesiology 1961;22(5)773-80.

22. Bellville JW, Bross IDJ, Howland WS, Postoperative nausea and vomiting IV: factors related to postoperative nausea and vomiting. Anesthesiology 1960;21(2):186-93.

23. Beattie WS, Linblad T, Buckley DN, et al. The incidence of postoperative nausea and vomiting in women undergoing laparoscopy is influenced by the day of the menstrual cycle. Can J Anaesth 1991;38(3):298-302.

23. Honkavaara P, Lehtinen AM, Hovorka J, et al. Nausea and vomiting after gynaecological laparoscopy depends upon the phase of the menstrual cycle.Can J Anaesth 1991;38:876-9.

25. Purkis IE. Factors that influence postoperative vomiting. Can Anaesth Soc J 1974;11: 335-53.

26. Crocker JS, Vandam LD. Concerning nausea and vomiting during spinal anaesthesia. Anaesthesiology 1959; 20: $587-$ 90 .

27. Green NM,Physiology of spinal anaesthesia.3rd ed. Baltimore (MD):Williams and Wilkins,1981:258-60.

28. Yoshitaka Fujii, Hiroyoshi Tanaka, Mutsuko Ito. Treatment of vomiting after paediatric strabismus surgery with Granisetron, Droperidol and Metoclopramide. Opthalmologica 2002; 216: 359-362.

29. Yarker YE, McTavish D, Granisetron. An update of its therapeutic use in nausea and vomiting induced by antineoplastic therapy.Drugs.1994;48:761-93. 